\title{
Imagination in practice
}

\author{
P Anne Scott University of Stirling, Stirling, Scotland
}

\begin{abstract}
Current focus in the health care ethics literature on the character of the practitioner has a reputable pedigree. Rather than offer a staple diet of Aristotelian ethics in the undergraduate curricula, perhaps instead one should follow Murdoch's suggestion and help the practitioner to develop vision and moral imagination, because this has a practical rather than a theoretical aim.'

The imaginative capacity of the practitioner plays an important part in both the quality of the nurse's role enactment and the moral strategies which the nurse uses. It also plays a central part in the practitioner's ability to communicate with a patient and in the type of person which the practitioner becomes.

Can the moral imagination be stimulated and nurtured? Some philosophers and literary critics argue that not only is this possible, but that literature is the means of doing so. If this is the case then a place should be made for literature in already crowded health care curricula.
\end{abstract}

\section{Introduction}

A current interest in both nursing and medical literature is the character of the health care practitioner and its influence on the type of care which the practitioner provides for patients or clients. ${ }^{2}$ Considerations of character move one into the domain of moral discourse. In speaking about the moral dimensions of both nursing and medical practice one needs to consider issues of role enactment and moral strategy. ${ }^{3}$ The importance of these concepts was articulated by Downie in the 1960s within the wider social context. ${ }^{4}$ These issues are also directly related to the type of care which the practitioner provides for patients or clients, and to the character of the practitioner. Moral strategy refers to when and how we go about doing something of moral relevance; for example when and how a patient is asked to participate in a clinical trial. Role enactment refers to those qualities which an individual brings to his or her functioning in a role. These qualities are elements of the character and are thus not reducible to aspects of the role.

\section{Key words}

Moral imagination; moral strategy; role enactment.
When one wishes to consider characteristics of the practitioner, particularly those related to the issues of role enactment and moral strategy, one is talking of virtue in the Aristotelian sense of the word. ${ }^{5} \mathrm{~A}$ further element which is needed when one considers role enactment and moral strategy is that of an active moral imagination. This is because the type of "agent-attention" 6 which is needed for high-quality role enactment and sensitive moral strategy presupposes activity of the moral imagination.

It is difficult to describe adequately what the moral imagination is. For our present purposes, I suggest that moral imagination is that aspect of the imagination which potentially becomes active in the moral agent's attempt to consider what moral decisions to make: that human faculty which allows "gut-reaction" to be used and moderated into the perceptual schema and which enables the moral agent to build up a multi-dimensional understanding of a situation - including a reasonably complex understanding of the situation of the actors involved. This faculty comprises three elemental influences: reason, gut-response and something akin to Humean fancy.

I suggest that it is at least partially activity of the moral imagination which allows the sensitive nurse or doctor, for example, to perceive the non-verbal cues and attend to patients sufficiently to know when the patient is capable of coping with bad news, rather than merely stating such news in a cold, factual way, without any attempt to consider if the time is ripe. Respecting patient autonomy is important. However, given the vulnerability which illness brings, so also is a consideration of the particular situation of the individual patient. This process of consideration of the particular situation is facilitated by an active moral imagination. ${ }^{2} 3$

I am suggesting, therefore, that the development of an active moral imagination is necessary in the preparation of the health care practitioner. How might this development of the moral imagination be supported within the educational preparation which novice practitioners undergo?

Murdoch's idea, that by paying attention (in Weil's sense of a just and loving gaze directed upon a person or object) properly, selflessly, one comes to see what must be done, ${ }^{7}$ has at least a strong intuitive appeal. However as Murdoch points out: 
"I can only choose within the world I can see, in the moral sense of 'see' which implies that clear vision is a result of moral imagination and moral effort."8

She also suggests that:

“. . . where virtue is concerned we often apprehend more than we clearly understand and grow by looking."9

It is a noteworthy point that in medicine, and in nursing, students are being educated in what clinical features - which signs and symptoms should be noted as likely to be of relevance. It is also noteworthy that one of the results of this is that the student, perhaps unconsciously, is becoming aware of what can be ignored. The student is actively trained to filter out large chunks of information while being encouraged to focus on, usually (quite reasonably) physical complaints. (The problem is that sometimes the physical complaint is symptomatic of the only partially physical or the nonphysical; and sometimes problems which can have a significant effect on the patient's treatment are not of a physical nature. Current developments in medical and nursing curricula are suggesting a change in focus). ${ }^{10}$

Awareness of the psychosocial dimension of illness sensitises one to the idea that a patient may not overtly show the effects of hospitalisation, or of being socialised into the patient mode of operation. The dehumanising effects of being ignored or depersonalised by health care staff may not be readily evident to staff whose encounters with a patient are relatively brief. However, such encounters may harm the patient (and the staff involved for that matter); and they do carry moral evaluation. Is the health care practitioner morally responsible for interactions with patients, (or other professionals) the effects of which the practitioner does not see, or is not consciously aware of?

It seems that the answer to the above question must contain the phrase "it depends". It depends on whether it is reasonable to expect that the practitioner should be aware of her impact on the patient, or the impact of the institution, or a certain diagnosis, or a certain treatment, on the patient.

If certain actions or attitudes would be objected to, found wanting, or found to cause harm to a person in ordinary social interactions there is at least a good case to be made for suggesting that they will cause the same effect in a patient - professional interaction, unless they take place in a clearly defined situation in which both parties are aware of their own needs and desires, and of the effect which these have on the other participating party. For example, to stick a glass tube in another person's mouth in the middle of a public bar or a shop could be described as assault. In a doctor's surgery the person is probably having her temperature taken. However, to strip a person naked in a public ward (or indeed in $\stackrel{\mathbb{Q}}{\mathrm{a}}$ single room), leaving the person totally exposed $\frac{\text { f5 }}{7}$ surely not acceptable; any more than it would be acceptable to demand that a customer strip in department store.

It would appear that many incidents similar the metaphorical sense) to stripping a patient naked in a public ward become equivalent, in the mind of many health care practitioners, to taking a patient制 temperature. Failure, on the part of the health cares professional, to listen when a patient tries to com municate that which she feels is information relevar to her condition, failure to respect a person's (patient's) rights or human dignity, failure to see the patient as a person, all fit into this category.

This type of failure results from a problem with the quality of role enactment of particular practitiores ers. It seems likely that this problem may arise from a lack of sympathy and/or empathy with the patienor One cannot sympathise or empathise with a person 9 one cannot imaginatively enter the world of that par= ticular person. To sympathise means to have affinity with or to share another's interests and/\% emotions. To have an affinity with or to share the interests or emotions of another presupposes common understanding or the ability to identiff with the perspective of the other person. In a sinflat way, to empathise with another person, by de tion, means the ability to understand and imagồं tively enter into another person's feeling Therefore, one cannot sympathise or empathise wi a patient if one cannot imaginatively enter into the world of the particular patient with whom one is contact. The problem would thus seem to be one ff lack of imagination.

Nurses (and other health care practitioners) ca reasonably be expected to have the imaginative sen sitivities which would allow and/or encourage feelings and attitudes of sympathy and empatis between the practitioner and the patient. These are necessary qualities in practitioners who describ\& themselves as belonging to the caring professions. also seems that practitioners can and should be held responsible for lacking these qualities or characteris tics when it causes harm to patients (or indeed then selves as persons).

\section{Imagination, what is its relevance?}

An analysis of the concept of imagination is beyonet the remit of this paper. Some clarification of that aspect of imagination which is of concern in this papt may be achieved by stating that it is not the grosser perceptual aspects of imagination which are of interest in this instance, but a fine tuning of the ima of ination. The former aspects of imagination are dio cussed in depth by Hume, ${ }^{11}$ Kant ${ }^{12}$ and Warnock ${ }_{\Omega}{ }^{3}$ for example. Imagination, in Warnock's words, "bridges the gap between sensory data and intelligible thought". ${ }^{13}$ 
Evidently it is not this type of survival imagination which appears to be lacking in the health care practitioner who strips a patient naked in public or who carries on a teaching round while an old lady tries to use a bed pan. ${ }^{14}$ It is possible to argue that in this sort of situation the fine tuning of the imagination may be missing. By "fine tuning" is meant that aspect of the imagination which allows the nurse to perceive, in this particular patient, personhood; that aspect of the imagination which allows the practitioner to believe not only in the continuous existence of this particular patient, but which allows her to believe that here exists a human being: "a person such as I". This is the aspect of the imagination which in the words of Henry James allows one to be "finely aware and richly responsible". ${ }^{15}$ It seems that it is something like this type of imagination which Murdoch refers to as the "moral imagination". 161

\section{Moral paralysis}

One may ask at this point why this type of imagination appears to be important for the health care practitioner. Are practitioners not too busy trying to get on with their jobs to have time to worry about being "finely aware and richly responsible"? Inherent in this kind of criticism may be the very real fear experienced by some teachers of health care ethics that too much concentration on imagination and imaginatively identifying with patients may induce a moral and professional paralysis.

My reply is as follows: if health care professionals are willing to take upon themselves ultimate responsibility for decisions that can have a profound impact on the lives of their patients, then it is vital that these same practitioners clearly understand the possible or likely implications of their decisions from within the psychosocial context of the patient, rather than simply consider the medical implications. Therefore practitioners have a duty actively to engage with their patients at a level which will allow the practitioners to gain insight into the patients' lives in order to get a clearer perception of the likely implications of decision A or treatment B.

I suggest that this engagement only comes through activity of the moral imagination. This activity of the moral imagination is not a floundering at the level of uneducated emotion; which can indeed lead to paralysis, or perhaps the many incidences of burnout which one sees referenced in the literature. It is instead the activity of a faculty which has been nurtured and developed in the practitioner. A faculty akin, I suggest, to an intellectual virtue in Aristotle's sense of the term ${ }^{5}$; or more particularly a faculty directly relevant to the Aristotelian virtue of phronesis. It is this close connection with phronesis which leads to my suggestion above that the faculty of the moral imagination is in fact a composite faculty.
I would wish to argue that activity of the moral imagination is central to issues of moral strategy, role enactment and the personal characteristic of compassion. It is therefore at least indirectly related to the quality of health care which members of the general public receive. ${ }^{23}$ If this is so then educating the moral imagination is an important function of the education of a health care practitioner.

It is impossible to achieve much of the understanding which compassion requires without, to some extent, entering imaginatively into the world of the person who is the patient. For example it is not possible to understand the meaning or impact which breast cancer has for this thirty-six-year-old woman unless the practitioner also learns of and takes into consideration the fact that this young woman has five small children and an alcoholic husband. This allows the practitioner imaginatively to identify with this woman from within the context provided by this extra information.

Again a major coronary is a serious condition for any patient to face; the implications of this condition for $\mathrm{Mr}$ Jones cannot be more than glimpsed at unless it is also known that he is a widower who is responsible for the welfare of a son with uncontrolled epilepsy and Korsakoff's amnesia.

It may be suggested that though these extra bits of a patient's social history may be useful to know they are not vital. I suggest that possibly the only time in a patient's treatment that such information is not directly relevant to his treatment programme is in situations of life or death. For example during cardiac resuscitation the only really relevant information is "is the heart beating?" and "is the patient breathing?" If a patient is not responding to treatment, or is not responding as well as expected, or if he is refusing to take any treatment, apparently irrelevant bits of his social history may provide the answer to the problem. (Kleinman discusses such cases, for example that of Mrs Melissa Flower) ${ }^{17}$ It may also provide sufficient context, sufficient story, for the practitioner to begin imaginatively to identify with the particular patient.

\section{Non-compliance}

Patients are unlikely (unless desperate) even to try to communicate adequately with practitioners who are unable to establish a rapport with them or evince sympathy/empathy or compassion. This failure can potentially cause the patient harm through inappropriate treatments or through non-compliance with treatment regimes. These factors alone seem to provide good reasons to try to help nurses and doctors develop the capacities necessary to enable them to provide adequate humane care for their patients. But there is another relevant consideration.

If the practitioner continually fails to reach common ground with her patients in terms of developing an appreciation of what sickness means for 
them in their lives and world, then it would appear that not only the patient may be damaged. Murdoch suggests that we "grow by looking". ${ }^{7}$ If one does not look, one does not learn to see. At the very least this causes one to stagnate or at worst one is diminished by the experience.

To fail to see or to understand is to be oblivious of the reality of a situation. To be oblivious to a reality means that this reality has failed to enter one's world. One may stagnate behind a self-protective wall or one may be forced to channel one's energies into strengthening the wall, resulting in a shrinking of one's own humanity. Murdoch ${ }^{7}$ and Griffin ${ }^{18}$ suggest that such stagnation and shrinking is the result of self-protective selfishness. A pertinent question here is: "is it selfishness or is it that the painfulness of what one sometimes witnesses, prevents one from being able to 'see"'?19

One may certainly witnesses events so painful that the desire in one not to look, not to see, is overwhelming. It is this lack of insight into the human condition that makes the completely virtuous state a great deal more difficult to attain than either Aristotle or Murdoch suggest. ${ }^{57}$ It is also precisely because health care practitioners are almost daily faced with this reality in an unadulterated, undisguised way, that their ability to look, to see, to live with and grow from such experiences is all the more necessary. For if such abilities are not fostered, desiccation of the personality, burnout, attrition from the professions and poor patient care are almost inevitable scenarios.

The potential for this type of scenario to befall the practitioner should be recognised more widely than it would appear to be at present. This problem has certainly been identified in sociological literature. It is occasionally described as an undesirable aspect of the process of professional socialisation for a number of practitioners. This potential for the desiccation of personality to occur seems to provide another reason for supporting the development of the practitioner's moral imagination. If the practitioner can imaginatively identify with a particular patient during certain trying situations the focus of the practitioner's attention is on the patient rather than on himself and his own particular needs (conscious or unconscious). Therefore, the practitioner's practice is patientcentred and in that sense patient-directed or patientfocused, rather than practitioner-centred or practitioner-focused. This can result in an enriching and an enlarging of the perspective of the practitioner.

It seems that the imaginative capacity of the practitioner plays a very important role in the quality both of the practitioner's role enactment and the moral strategies which the practitioner uses. It may also play a central role in the practitioner's ability to communicate with a patient and in the type of person which the practitioner becomes. In a useful analysis of the concept of caring in clinical practice Griffin ${ }^{18}$ makes some relevant remarks:

"To be able to care what must a nurse first be like? If. she or he is an active participant in an importants human experience, it is necessary that she is able and willing to understand the features of this situation and that the nurse is 'a mind in possession of its? own experience', (not everyone understands much of what happens to them) receptive too, to painfub emotional questions. Part of this understanding mays be built up by reflection. . . . Its essential value is related to the maturity of the individual in being able to clear his mind of self-oriented concerns and obsessions. It requires some liberation from self centeredness towards awareness of another's needs ${ }^{\Phi}$ (To achieve this is one of the major aims of a morat education such as many nurses and others may well not have had)."

Griffin's suggestion that many nurses may no은 receive the relevant type of education (moral educa- tion) to allow them to perceive accurately and understand the needs of their patients shoulde provide food for thought for those of us who try tô teach ethics to nurses (and other health care practitioners). This seems to raise the following questions $\ddot{\vartheta}$ "what are educators attempting to do, when they \&yy to teach ethics to health care practitioners?" "Whap

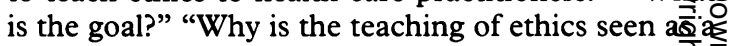
good idea, or in more and more instances a neces sary part of the curriculum?" The answer which $\mathbb{b}$ offer is that ethics is taught in an attempt to help the student become a better practitioner; better in the sense of more humane, more compassionate, more caring towards the persons who are the practitioner's patients.

\section{Can the moral imagination be stimulated and nurtured?}

"The claim seems to be that if you really vividlos experience a concrete human life, imagine what it' like to live that life, and at the same time permie yourself the full range of emotional responses to that concrete life, you will (if you have at all a good mora‥ start) be unable to do certain things to that person Vividness leads to tenderness, imagination to compassion. The patient effort to see moderates the coarseness of which political horror is made." 20 N

The notion of "a good moral start", bracketed ir? the above quote from Nussbaum, is of course cruciab here. It is an Aristotelian idea and is supportive of my idea of activity of the moral imagination being an intellectual virtue. The intellectual virtues, in an Aristotelian framework, are built upon a foundation of moral virtues, the existence of which depends or "a good moral start". 5 This suggests that attempts t\& educate the moral imagination come secondary tQ the need to consider the character of entrants to the health care professions. This is perhaps an idea that 
has been highlighted by the Allitt Inquiry. ${ }^{21}$ The point being that attempts to stimulate, develop and educate the moral imagination will "fall on stony ground" unless it is viewed as an element in the developing character of the practitioner.

In the literature there is a growing school of thought which suggests that the answer to the question "can the moral imagination be stimulated and nurtured?" is a resounding "yes". The theory is that the moral imagination can be stimulated and nurtured through the use of the humanities, perhaps particularly the serious reading of literature; especially certain types of novels. Nussbaum, quoted above, is a persuasive contemporary supporter of this theory. Further support for the theory comes from the field of literary criticism. For example Price:

"Our capacity to enter imaginatively into the lives of others is a process of irreversible growth. It provides us with knowledge we can never resign and must act upon."

He goes on later to argue:

"What we in turn recognise as readers is the need if we are to read with any sense at all - to feel ourselves into the moral imagination of the characters. We may shift back and forth, from inside to outside . . . but we cannot begin to understand the experience the novel presents without some participation in the moral realities within which its characters live." 22

Further support for this view is found in medical humanities literature, for example, Trautmann, ${ }^{23}$ Brody, ${ }^{24}$ Downie. ${ }^{25}$

The notion that literature can affect people's behaviour is certainly not new. Plato in The Republic bans poets and artists because of the potentially detrimental effects of their work on the general population. ${ }^{26}$ Censorship laws are based on the same premise. If some forms of literature or art can be deemed to have bad influences on people then it seems quite reasonable to suggest that other forms of literature and art can influence people to the good.

Nussbaum, following the Aristotelian tradition, suggests that one of the more effective ways of developing and nurturing this element, which recognises the importance of perception and emotion as well as particularity in ethics, is through the use of the novel. ${ }^{20}$ Attentive reading of certain types of novel (such as those of Henry James and Charles Dickens, according to Nussbaum) helps develop moral sensitivity and moral imagination by inviting the reader to go beyond her immediate experience, to see the importance of the specific context and yet also to perceive the links of common humanity which bind the reader to characters in stories. It is perhaps not too difficult a step from here to developing sympathetic identification with the patients one meets in clinical practice.

This notion of course raises two further issues. Firstly if literature can stimulate the moral imagination how can it be ensured that this is a positive rather than a detrimental influence on practitioner character and patient care? And secondly the literature which scholars such as Nussbaum suggest may not be immediately accessible to the average medical or nursing student, therefore how does one decide what literature to use?

An answer to the first concern is not easy, but must be rooted in an acceptance of certain ideals of clinical practice which are based on explicit articulation of the core concepts of practice: such as "care" and "treatment". The answer is also directly related to an identification of dispositions of character which are seen to be desirable in the practitioner.

In answer to the second problem Nussbaum concentrates on the novel as a means of moral education. Many educators in the medical humanities use also, or exclusively, contemporary short stories, drama, poetry (Coles, ${ }^{27}$ Trautmann, ${ }^{23}$ and Downie. ${ }^{25}$ I suggest there are advantages in using a mixture of texts, and a mixture of media - both printed and visual. Use of novels and film has the advantage of historical perspective, and lengthy descriptions of context and character. They are also good sources for developing history-taking skills in students - an idea which exercised Kleinman. ${ }^{17}$ However, within the realities of a crowded curriculum one must be realistic in one's expectations of students. Poetry and short stories can often focus the mind sharply and effectively on an issue of concern.

The development of a syllabus is not my intention here. However, there is a growing variety of help in the literature, for teachers of health care ethics who wish seriously to consider the suggestions in this paper and to attempt to act upon them (for example 172023242527 ). A point that is worth making, I think, is that it is useful to become reasonably familiar with the second level curriculum in that it will give the teacher of medical or nursing humanities some insight into which texts our students will, initially, find accessible.

Murdoch advises focusing on certain works of art, and there is evidence of this being considered in medical and nursing education. ${ }^{25}$ This may be very useful for those who find art accessible. However, literature has two advantages in this area: firstly most of our students will have been exposed to literature until midway through their secondary education, if not afterwards. Therefore one is not working from scratch in this area. Secondly literature will provide first-order and also second-order concepts with which to enrich the language and thought processes of our students. In a context where there is growing subsumption of the language of the market place into the thinking, writing and policy-making about health care practice, I suggest that this is not an 
unimportant consideration. Language influences thought ${ }^{28297}$ ) and it is difficult to see how verbal thought does not affect the boundaries of imaginative activity

\section{Conclusion}

From what is being argued above it seems to be the case that moral imagination is important to the quality of a practitioner's role enactment, the moral strategies which the practitioner uses and the practitioner's ability to communicate with patients. The quality of care which a patient receives from a practitioner is not only to do with technical, clinical skills but also with the practitioner's ability to listen and communicate, as well as with the quality of the practitioner's role enactment and moral strategy. Therefore, it seems that an active moral imagination is important to the type of care which patients receive from health care practitioners.

It is further being suggested by many theorists that the moral imagination can be stimulated and nurtured through the humanities, particularly literature. If this is the case, a place should be made for the use of literature in the already crowded curriculum of medical and nursing students. This, of course, is not a new idea. However, I think that an attempt to link activity of the moral imagination directly to certain aspects of patient care is a significant factor in giving weight to the demand.

P Anne Scott, BA, MSc, PhD, RGN, is Senior Lecturer in the Department of Nursing and Midwifery, University of Stirling, Stirling FK9 4LA.

\section{References}

1 Murdoch I. Vision and choice in morality. Proceedings ofthe Aristotelian Society [supplementary] 1956; 30: 32-58.

2 Scott PA.Virtue, imaginative identification and the health care practitioner. Unpublished $\mathrm{PhD}$ thesis, University of Glasgow, 1993.

3 Scott PA. Care, attention and imaginative identification in nursing practice. Fournal of Advanced Nursing 1995; 21: 1196-1200.

4 Downie RS. Government action and morality. London: MacMillan \& Co, Ltd, 1964.

5 Aristotle. The nicomachean ethics. Translated by Sir David Ross, revised by JL Ackrill and JO Urmson. Oxford: Oxford University Press, World Classics Series, 1980 .
6 White AR. Attention. Oxford: Basil Blackwell, 1964.

7 Murdoch I. Sovereignty of good. London: Routledge andT Kegan Paul, 1970.

8 See reference $7: 37$.

9 See reference $7: 31$.

10 General Medical Council. Tomorrow's doctors: recom $\stackrel{\overline{\overrightarrow{0}}}{\longrightarrow}$ mendations on undergraduate medical education. London? General Medical Council, 1993.

11 Hume D. A treatise on human nature [2nd ed]. Tex revised by $P$. Nidditch. Oxford: Clarendon Press, 1978. $\widehat{\Phi}$ Hume D. An enquiry concerning the human understanding and an enquiry concerning the principles of morals. Oxford: $\$$ Clarendon Press, 1902.

12 Kant E. A critique of judgment. New York: Hefner, 1951.

13 Warnock M. Imagination. London: Faber and Faber, 1976.

14 Caplan AL. Can applied ethics be effective in health care practice and should it strive to be? Ethics 1983; 93:W 311-9.

15 James $H$. The art of the novel. New York: Charlesct Scribner and Sons, 1907.

16 Murdoch I. See reference 1 and also Murdoch I.Metaphysics as a guide to morals. London: Chatto andT Windus, 1992.

17 Kleinman A. The illness narratives: suffering, healing and the human condition. New York: Basic Books Inc, $1988 \stackrel{20}{2}$

18 Griffin AP. A philosophical analysis of caring in nursing. Fournal of Advanced Nursing 1983; 8:0 289-295.

19 This very relevant question was raised by an ano mous referee of an earlier draft of this paper.

20 Nussbaum MC. Love's knowledge. Oxford: Oxf University Press, 1990.

21 Clothier C, chairman. The Allitt inquiry: independen inquiry relating to deaths and injuries on the children's ward $\mathrm{D}$ at Grantham and Kesteven General Hospital during the $\overrightarrow{\hat{\sigma}}$ period February to April 1991. London: HMSO, 1994.3

22 Price M. Forms of life: character and moral imagination in? the novel. New Haven: Yale University Press, 1983.

23 Trautman J. Healing arts and dialogue - medicine and literature. Illinois: Southern Illinois University Press,,$\frac{\mathrm{C}}{3}$ 1981.

24 Brody H. Stories of sickness. New Haven: Yale University Press, 1987.

25 Downie RS, ed. The healing arts: an Oxford illustrated anthology. Oxford: Oxford University Press, 1994.

26 Plato. The Republic. Translated by D Lee.을 Harmondsworth: Penguin, 1974.

27 Coles R. The call of stories: teaching and the moral imagination. Boston: A Peter Davidson Book, Houghton Miffin, 1989.

28 Vygotsky L. Thought and language. Revised and edited by Alex Kozulin. Massachusetts: MIT Press, 1986.

29 Diamond C. Losing your concepts. Ethics 1988; 98: 255-277. 